\title{
Isolate-Cultivar Interactions, In Vitro Growth, and Fungicide Sensitivity of Fusarium oxysporum Isolates Causing Seedling Disease on Soybean
}

\author{
D. R. Cruz Jimenez, M. L. Ellis, G. P. Munkvold, and L. F. S. Leandro, ${ }^{\dagger}$ Department of Plant Pathology and Microbiology, Iowa State \\ University, Ames 50011
}

\begin{abstract}
Fusarium oxysporum is frequently associated with soybean root rot in the United States. Information about pathogenicity and other phenotypic characteristics of $F$. oxysporum populations is limited. The objective of the research described herein was to assess phenotypic characteristics of $F$. oxysporum isolates from soybean, including the interaction between isolates and soybean cultivars, fungal growth characteristics in culture, and sensitivity to fungicides commonly used as seed treatment products. The pathogenicity of 14 isolates was evaluated in rolled-towel and Petri-dish assays using 11 soybean cultivars. In the rolled-towel assay, seed were inoculated with a conidial suspension and disease severity was observed. In the Petri-dish assay, F. oxysporum isolates were grown on $2 \%$

water agar and seed were placed on the $F$. oxysporum colony to observe the symptoms that developed. Cultivars differed in susceptibility to $F$. oxysporum, and significant $(P=0.0140)$ isolate-cultivar interactions were observed. $F$. oxysporum isolates differed in radial growth on potato dextrose agar at $25^{\circ} \mathrm{C}$. Pyraclostrobin and trifloxystrobin reduced conidial germination with average $50 \%$ effective concentration $\left(\mathrm{EC}_{50}\right)$ of 0.15 and $0.20 \mu \mathrm{g}$ active ingredient (a.i.)/ml, respectively. Ipconazole reduced fungal growth with average $\mathrm{EC}_{50}$ of $0.23 \mu \mathrm{g}$ a.i./ml, whereas fludioxonil was ineffective. Our results illustrate soybean $F$. oxysporum isolate variability and the potential for their management through cultivar selection or seed treatment.
\end{abstract}

Fusarium root rot is an important soybean (Glycine max (L.) Merr.) disease in the United States and Canada. The common symptoms of Fusarium root rot include wilting, damping-off, slow emergence, root rot, and vascular discoloration (Nelson 1999). Diverse species of Fusarium have been associated with soybean root rot. Although fungal populations may vary due to geographic and environmental conditions, the most prevalent and frequent species of Fusarium recovered from roots, soil, or crop residues in a number of surveys performed across soybean fields in the United States included Fusarium oxysporum Schltdl., F. solani (Mart.) Sacc., and F. graminearum Schwabe (Díaz Arias et al. 2013b; Leslie et al. 1990; Marburger et al. 2015; Nyvall 1976; Zhang et al. 2010).

F. oxysporum is composed of diverse cryptic species known as the F. oxysporum species complex (FOSC) (O'Donnell et al. 2009). Members within this group are responsible for causing vascular wilts, damping-off, and root rots in a wide range of economically important crops (Michielse and Rep 2009; O’Donnell et al. 2009). In previous studies, new species of Fusarium have been identified within the FOSC, including F. commune K. Skovg., O’Donnell \& Nierenberg (Skovgaard et al. 2003), which was previously reported to be a component of the FOSC from Iowa soybean root isolates (Ellis et al. 2013). Isolates of $F$. oxysporum associated with soybean seedling and root rot diseases in Iowa were previously placed into five clades within the FOSC, whereas $F$. commune isolates correspond to clade 6 within the same complex (Ellis et al. 2014).

Soybean isolates within the FOSC are genotypically and phenotypically diverse. Pathogenic capabilities of these isolates to soybean range from highly pathogenic to nonpathogenic and saprophytic (Ellis et al. 2014; Laurence et al. 2014). Even though $F$. oxysporum is the species most commonly associated with soybean root rot, there have been inconsistent findings about its role and importance in the Fusarium root rot complex. For example, in greenhouse studies using artificially infested soils, $F$. oxysporum produced the greatest seed

${ }^{\dagger}$ Corresponding author: L. F. S. Leandro; E-mail: 1leandro@iastate.edu

Funding: This research was funded by the United Soybean Board and the North Central Soybean Research Program.

Accepted for publication 27 March 2018.

() 2018 The American Phytopathological Society mortality and caused less severe root rot compared with $F$. graminearum, $F$. avenaceum, and $F$. tricinctum (Zhang et al. 2010). In artificially infested microplots, $F$. oxysporum did not significantly reduce yield, but regression analysis performed on individual $F$. oxysporum isolates indicated a negative correlation between root rot severity and yield (Díaz Arias et al. 2013a). At present, little information is available regarding the range of aggressiveness of $F$. oxysporum isolates toward different soybean cultivars. One of the first reports regarding $F$. oxysporum suggested a range of sensitivity between a single F. oxysporum isolate and multiple cultivars (Leath and Carroll 1982).

Currently, one of the most efficient disease management strategies to control seedling diseases in soybean is the use of fungicide seed treatments (Munkvold et al. 2014). These are typically used to prevent infections by soilborne pathogens that cause pre- and postemergence damping-off, in circumstances where environmental conditions cause delayed germination. The use of seed treatments on soybean is becoming more common because many commercial seed treatments generally include a combination of multiple fungicides as well as a nematicide (Hartman et al. 1999; Mueller et al. 2013). Among the most widely used active ingredients, the quinone outside inhibitors (QoI), such as trifloxystrobin and pyraclostrobin are extensively used on soybean and maize (Zea mays L.) in combination with fludioxonil to improve efficacy against a wide range of soilborne pathogens, including Fusarium spp. (Broders et al. 2007a; Munkvold 2009). However, QoI have site-specific activity and are characterized by a high risk for resistance development (Mueller et al. 2013). Increased insensitivity to QoI have been reported for Fusarium spp. in tomato (Chapin et al. 2006), Alternaria alternata in citrus and apple (Mondal et al. 2005; Reuveni and Sheglov 2002), and Pythium spp. in soybean (Broders et al. 2007b).

The objectives of this research were to clarify the importance of $F$. oxysporum as a soybean seedling pathogen by (i) studying the reactions of soybean cultivars to different $F$. oxysporum isolates collected from commercial soybean fields in Iowa, (ii) examining the impact of commonly used fungicidal active ingredients on conidial survival and radial growth of $F$. oxysporum isolates, and (iii) comparing radial growth of $F$. oxysporum isolates under optimum temperature conditions.

\section{Materials and Methods}

Inoculum and plant source. Fourteen $F$. oxysporum isolates collected from symptomatic soybean roots across Iowa in 2007 (Díaz Arias et al. 2013a) were used in all experiments (Table 1). Isolates 
originated from single conidia and were maintained on silica gel beads at $4^{\circ} \mathrm{C}$ until use. These 14 isolates had been previously tested in greenhouse studies, and information regarding their aggressiveness in causing root rot and seedling mortality on the soybean cultivar Asgrow 2403 (soybean death syndrome [SDS] susceptible; Monsanto Company, St. Louis) was available (Díaz Arias et al. 2013a). In addition, the same isolates had been previously characterized phenotypically in a rolled-towel assay with the $F$. oxysporumsusceptible cultivar MN1805 (Ellis et al. 2014).

Each $F$. oxysporum isolate was grown on potato dextrose agar (PDA) for 7 to 14 days in an incubator at $25^{\circ} \mathrm{C}$ with a 12-h photoperiod in order to promote conidial formation. Macro or microconidia were collected by adding sterile distilled water (SDW) to the culture and gently scrubbing with a sterile stick. The suspension was passed through sterile cheesecloth to remove mycelial fragments. Inoculum concentration was calculated by counting conidia in a hemacytometer (Bright-line Hemacytometer; American Optical, Buffalo, NY) under the microscope, and conidial suspensions were adjusted to a concentration of $1 \times 10^{4}$ conidia $/ \mathrm{ml}$.

Eleven soybean cultivars were selected for these studies, including the $F$. oxysporum-susceptible cultivar MN1805. The cultivars were selected from a range of soybean maturity groups (MG), representing MG I to V, and represented a wide range of susceptibility to SDS and soybean cyst nematode (Table 2).

Rolled-towel pathogenicity assay. Fifteen soybean seeds were placed equidistantly, approximately $1 \mathrm{~cm}$ apart, in a row on a moist paper towel. Each seed was inoculated with $100 \mu l$ of a suspension of $1 \times 10^{4}$ conidia $/ \mathrm{ml}$. After inoculation, seed were covered with another moist towel to keep them in place and to provide moisture for germination, and the towels were rolled. There were three $F$. oxysporuminoculated rolls and one noninoculated roll (used as a control) per cultivar. Inoculations were performed with one $F$. oxysporum isolate on 11 soybean cultivars at a time. The 44 rolls were placed in a 25-liter bucket containing $300 \mathrm{ml}$ of distilled water and incubated for 7 days at room temperature $\left(25^{\circ} \mathrm{C}\right)$. Mock-inoculated rolls were confined within the bucket with a plastic tray to avoid cross contamination. One roll was considered an experimental unit, with 15 seeds or subsamples on each roll. Each of the $14 \mathrm{~F}$. oxysporum isolates were tested 1 at a time. The experimental design was a randomized complete block, in which each bucket was considered as a random factor for the statistical analysis. The experiment was conducted two times.

Table 1. Description of Fusarium oxysporum isolates collected from soybean roots across Iowa in 2007 (Díaz Arias et al. 2013a) and genotypic characterization, including mating type loci and clades within the $F$. oxysporum species complex (FOSC) (Ellis et al. 2014)

\begin{tabular}{|c|c|c|c|c|c|c|}
\hline \multirow[b]{2}{*}{ Isolate ID } & \multirow[b]{2}{*}{ County } & \multirow[b]{2}{*}{ Stage $^{b}$} & \multirow[b]{2}{*}{ Mating type } & \multirow[b]{2}{*}{ FOSC clade } & \multicolumn{2}{|c|}{ Type of conidia ${ }^{a}$} \\
\hline & & & & & Microconidia & Macroconidia \\
\hline FO36 & Lyon & V3 & MAT1-2 & 5 & $\mathrm{P}$ & A \\
\hline FO37 & Lyon & V3 & MAT1-2 & 5 & A & $\mathrm{P}$ \\
\hline FO38 & Hamilton & $\mathrm{R} 1$ & MAT1-2 & 5 & $\mathrm{P}$ & $\mathrm{P}$ \\
\hline FO39 & Lee & V3 & MAT1-2 & 5 & $\mathrm{P}$ & A \\
\hline FO40 & Butler & $\mathrm{V} 3$ & MAT1-1 & 3 & $\mathrm{P}$ & $\mathrm{P}$ \\
\hline FO41 & Jefferson & V3 & MAT1-1 & 6 & $\mathrm{P}$ & A \\
\hline FO42 & Lee & V3 & MAT1-2 & 2 & $\mathrm{P}$ & $\mathrm{P}$ \\
\hline FO43 & Crawford & $\mathrm{V} 2$ & MAT1-2 & 5 & $\mathrm{P}$ & $\mathrm{P}$ \\
\hline FO44 & Winneshiek & $\mathrm{V} 2$ & MAT1-2 & 5 & $\mathrm{P}$ & $\mathrm{A}$ \\
\hline FO45 & Lyon & V3 & MAT1-2 & 5 & $\mathrm{P}$ & $\mathrm{A}$ \\
\hline FO46 & Crawford & $\mathrm{V} 2$ & MAT1-2 & 5 & A & $\mathrm{P}$ \\
\hline FO47 & Dickinson & V3 & MAT1-2 & 3 & $\mathrm{P}$ & A \\
\hline FO48 & Crawford & V2 & MAT1-1 & 3 & A & $\mathrm{P}$ \\
\hline FO49 & Allamakee & V3 & MAT1-2 & 6 & $\mathrm{P}$ & A \\
\hline
\end{tabular}

${ }^{a}$ Type of conidia produced on potato dextrose agar after 7 days of incubation with a 12 -h light period at $25^{\circ} \mathrm{C} . \mathrm{P}=$ present and $\mathrm{A}=$ absent.

b Soybean developmental stage at the time of root sampling.

Table 2. Description of 11 soybean cultivars used to study their interaction with Fusarium oxysporum

\begin{tabular}{|c|c|c|c|c|c|c|c|}
\hline \multirow[b]{2}{*}{ Cultivar } & \multirow[b]{2}{*}{$\mathbf{M G}^{\mathbf{b}}$} & \multirow[b]{2}{*}{ Pedigree } & \multirow[b]{2}{*}{ Released } & \multirow[b]{2}{*}{ Developer reference ${ }^{c}$} & \multicolumn{2}{|c|}{$\begin{array}{c}\text { Disease } \\
\text { reactions }^{\mathbf{a}}\end{array}$} & \multirow[b]{2}{*}{ References } \\
\hline & & & & & SDS & SCN & \\
\hline Ripley & IV & Hodgson $\times$ V68-1034 & 1985 & Ohio ARDC and USDA-ARS & PR & $S$ & $\begin{array}{l}\text { Cianzio et al. 2016; Cooper et al. 1990; } \\
\text { Luckew et al. 2012; Tatalović } 2014\end{array}$ \\
\hline $299 \mathrm{~N}$ & II & $\ldots$ & $\cdots$ & Mycogen Seeds & $\mathrm{S}$ & MS & $\begin{array}{l}\text { Cianzio et al. 2016; Luckew et al. 2012; } \\
\text { Tatalović } 2014\end{array}$ \\
\hline Forrest & $\mathrm{V}$ & Dyer $\times$ Bragg & 1972 & Mississippi, Tennessee AES, and USDA & $\mathrm{R}$ & $\mathrm{R}$ & Hartwig and Epps 1973; Tatalović 2014 \\
\hline MAC02 & IV & $\ldots$ & $\ldots$ & University of Missouri & $\mathrm{S}$ & MR & Luckew et al. 2012; Tatalović 2014 \\
\hline MN1606 & I & $\ldots$ & $\ldots$ & $\ldots$ & $\mathrm{R}$ & S & Luckew et al. 2012; Tatalović 2014 \\
\hline СM396 & III & $\ldots$ & $\ldots$ & $\ldots$ & $\mathrm{R}$ & S & Schmidt et al. 2014; Tatalović 2014 \\
\hline MYC5171 & I & $\ldots$ & $\ldots$ & Mycogen Seeds & MS & S/MS & Luckew et al. 2012; Tatalović 2014 \\
\hline Williams 82 & III & Williams $(7) \times$ Kingwa & 1981 & Illinois AES and USDA & $\mathrm{S}$ & $\mathrm{S}$ & $\begin{array}{l}\text { Bernard and Cremeens 1988; } \\
\text { Schmidt et al. 2009; Tatalović } 2014\end{array}$ \\
\hline H2494 & II & $\ldots$ & $\ldots$ & $\ldots$ & S & S & Cianzio et al. 2016; Tatalović 2014 \\
\hline MN1805 & I & $\ldots$ & $\ldots$ & $\ldots$ & MR & $\mathrm{S}$ & Luckew et al. 2012; Tatalović 2014 \\
\hline Jack & II & Fayette $\times$ Hardin & 1989 & Illinois AES & MR & $\mathrm{R}$ & $\begin{array}{l}\text { Cianzio et al. 2016; Nickell et al. 1990; } \\
\text { Schmidt et al. 2009; Tatalović } 2014\end{array}$ \\
\hline
\end{tabular}


Disease severity was evaluated by two methods, as described by Ellis et al. (2011). Disease severity index (DSI) was calculated as the ratio between the length of discolored hypocotyl lesion and the total plant length, multiplied by 100 . When seed did not germinate and were completely colonized, they were assigned a DSI value of $100 \%$. Seedlings were also evaluated using a 1-to-5 severity scale, in which 1 = germination, no symptoms of disease or colonization on seedling; 2 = germination, little colonization of the seedling, 1 to $19 \%$ of the root with lesions; 3 = germination, some colonization of seedling, and 20 to $74 \%$ of the root with lesions; $4=$ germination, complete colonization of the seedling, and $75 \%$ or more of the root with lesions; and $5=$ no germination, complete colonization of the seed (Fig. 1). Root length, root weight, and plant length were also measured.

Petri dish pathogenicity assay. A Petri-dish assay was performed to test the aggressiveness of $14 \mathrm{~F}$. oxysporum isolates and 11 soybean cultivars following a methodology similar to what has been previously published (Broders et al. 2007b; Muyolo et al. 1993; Zhang and Yang 2000). A 3-mm-diameter plug from a 7-day-old PDA culture of an isolate of $F$. oxysporum was transferred to the center of a Petri dish containing $2 \%$ water agar, which was incubated for 4 days under a 12 -h photoperiod at $25^{\circ} \mathrm{C}$. Eight soybean seeds were then surface disinfested in a $0.5 \% \mathrm{NaOCl}$ solution for $2 \mathrm{~min}$ and rinsed twice with SDW for $2 \mathrm{~min}$. Seed were placed evenly spaced in the dish, approximately $1 \mathrm{~cm}$ from the edge of the fungal colony. Plates were incubated at $25^{\circ} \mathrm{C}$ for 7 days with a 12-h photoperiod. Disease severity was rated using a 0-to-3 scale, as outlined by Broders et al. (2007b): $0=100 \%$ germination, with no symptoms of root infection; $1=70$ to $99 \%$ germination, with lesion formation on the roots; $2=30$ to $69 \%$ germination, with coalesced lesions; and $3=0$ to $29 \%$ germination and all seed tissues colonized (Fig. 2). The experimental design was arranged in incomplete blocks with three soybean cultivars each, and cultivars Jack and MN1805 as controls on each of the blocks. Therefore, there were three incomplete blocks, each made up of three cultivars and the two check cultivars, Jack and
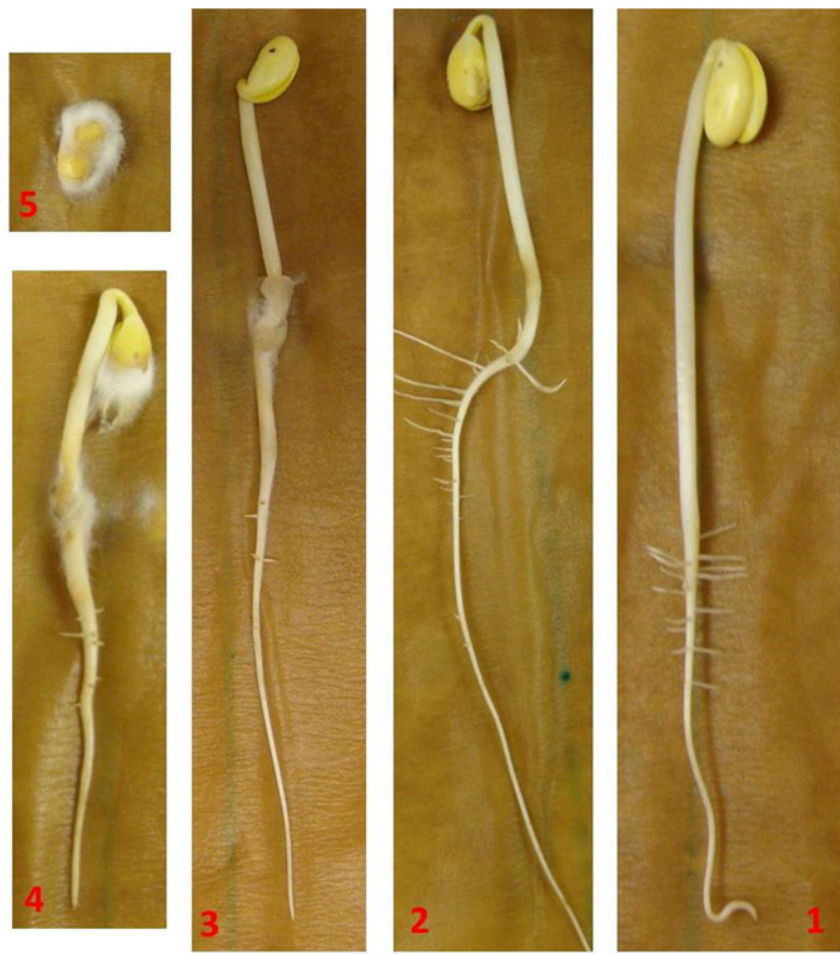

Fig. 1. Fusarium root rot disease intensity evaluated by an ordinal severity scale: $1=$ germination, no symptoms of disease or colonization on seedling; $2=$ germination, little colonization of the seedling, 1 to $19 \%$ of the root with lesions; $3=$ germination, some colonization of seedling, and 20 to $74 \%$ of the root with lesions; $4=$ germination, complete colonization of the seedling, and $75 \%$ or more of the seedling root with lesions; and $5=$ no germination, complete colonization of the seed.
MN1805. For each treatment combination of cultivar and isolate, there were three Petri dishes, and the experiment was conducted twice. Blocks were considered to be a random effect for the statistical analysis.

Radial growth on PDA. To compare the growth rate of the 14 F. oxysporum isolates, 5-mm-diameter mycelial plugs of each isolate were aseptically transferred from a 7-day-old PDA culture to the center of 90-mm-diameter PDA Petri dishes and incubated for 4 days at $25^{\circ} \mathrm{C}$, under a 12-h photoperiod (Balasu et al. 2015; Groenewald et al. 2006). Colony diameter was measured in two perpendicular directions on each plate, and an average was calculated after subtracting $5 \mathrm{~mm}$ (representing the diameter of the colonized plug) from the final values. The experiment was organized in a completely randomized design with four replicate plates per isolate, and the experiment was conducted twice.

Fungicide sensitivity assays. The 14 isolates were tested for sensitivity to growth inhibition by the fungicides ipconazole and fludioxonil. Technical-grade active ingredients (a.i.) ipconazole (Bayer CropScience, Research Triangle Park, NC) and fludioxonil (Syngenta Crop Protection, Greensboro, NC) were dissolved in

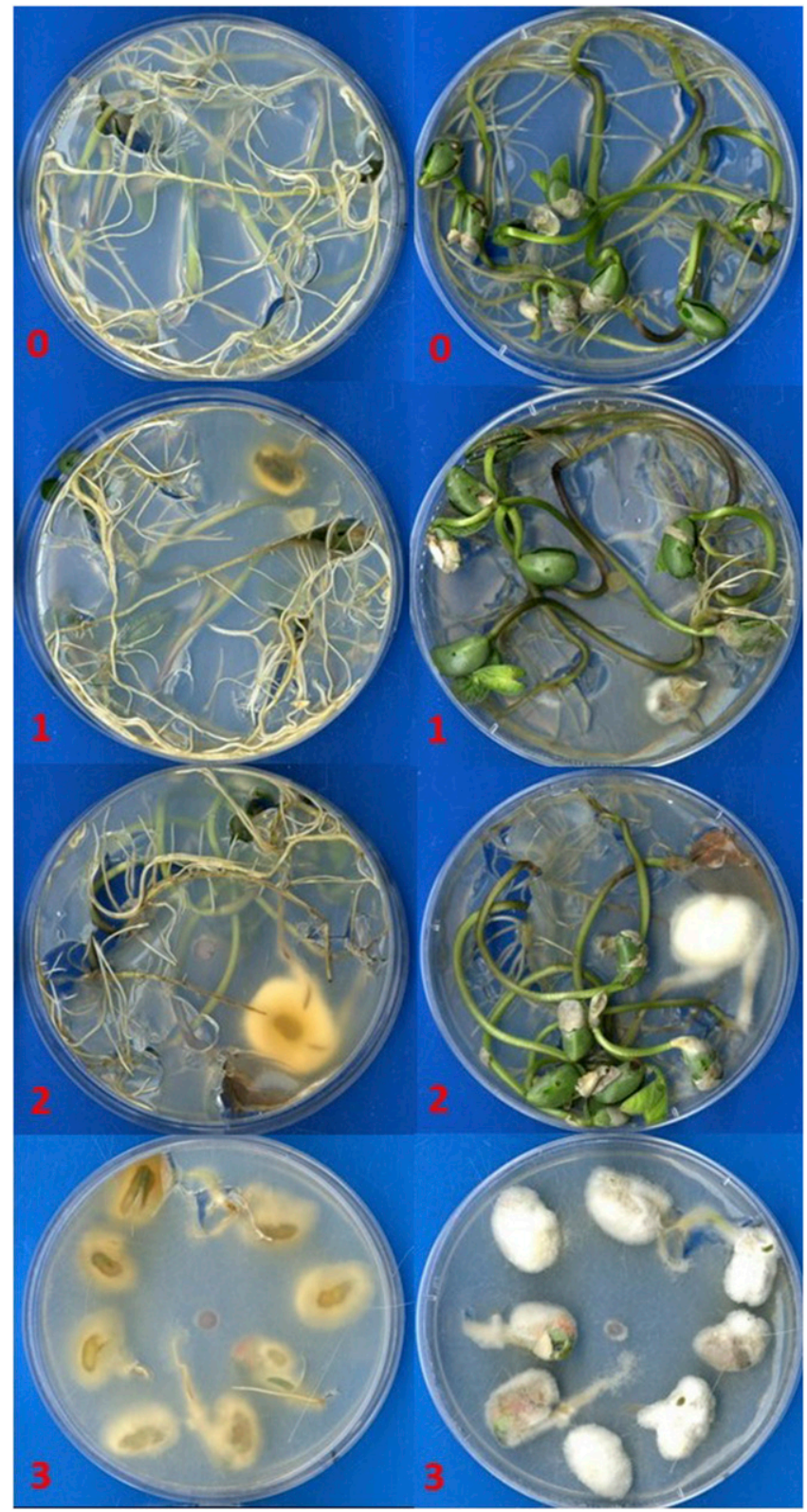

Fig. 2. Fusarium root rot disease intensity evaluated by a visual severity scale: $0=$ $100 \%$ germination, with no symptoms of root infection; $1=70$ to $99 \%$ germination, with lesion formation on the roots; $2=30$ to $69 \%$ germination, with coalesced lesions; and $3=0$ to $29 \%$ germination and all seed tissues colonized. 
acetone and added to PDA to obtain final concentrations of $0.01,0.1$, 1,10 , and $100 \mu \mathrm{g}$ a.i./ml. The nonamended control contained acetone at $0.1 \%$ (vol/vol) only. A colonized 5-mm plug was transferred from the original PDA cultures to 90-mm-diameter Petri dishes with the amended PDA. Colony diameter was measured after 4 days of incubation at $25^{\circ} \mathrm{C}$ with a 12 -h photoperiod, as described above. Percent growth inhibition was obtained by dividing the diameter of the colonies in the fungicide treatments by the mean colony diameter of the nonamended control. The experiment was organized in a completely randomized design with a factorial arrangement and two replicate Petri dishes per fungicide-concentration-isolate combination. The experiment was repeated three times.
Isolates were also tested for sensitivity to conidial germination inhibition by the QoI fungicides pyraclostrobin and trifloxystrobin. Technical-grade active ingredients pyraclostrobin (BASF Corp., Florham Park, NJ) and trifloxystrobin (Bayer CropScience) were dissolved in acetone to prepare stock solutions of $1 \times 10^{4} \mu \mathrm{g}$ a.i. $/ \mathrm{ml}$. PDA was amended with each active ingredient to obtain final concentrations of $0.01,0.1,1,10$, and $100 \mu \mathrm{g}$ a.i./ml. Salicylhydroxamic acid (SHAM, Sigma-Aldrich, St. Louis) was dissolved in methanol at a rate of $100 \mu \mathrm{g}$ a.i./ml to inhibit the alternative oxidase respiratory pathway. All dilutions, including the nonamended control, contained both acetone and methanol at $0.1 \%(\mathrm{vol} / \mathrm{vol})$ and SHAM at $100 \mu \mathrm{g}$ a.i./ml.

Table 3. Analysis of variance indicating the effects of soybean cultivar and Fusarium oxysporum isolates on disease severity index (DSI), visual severity rating, plant length (PL), root length (RL), and root weight $(\mathrm{RW})^{\mathrm{a}}$

\begin{tabular}{|c|c|c|c|c|c|c|c|c|c|c|c|c|c|}
\hline \multirow[b]{3}{*}{ Source } & \multirow[b]{3}{*}{ df } & \multicolumn{10}{|c|}{ Rolled towel } & \multirow{2}{*}{\multicolumn{2}{|c|}{$\begin{array}{c}\text { Petri dish } \\
\text { Severity }\end{array}$}} \\
\hline & & \multicolumn{2}{|c|}{ DSI } & \multicolumn{2}{|c|}{ Severity } & \multicolumn{2}{|c|}{ PL } & \multicolumn{2}{|c|}{ RL } & \multicolumn{2}{|c|}{ RW } & & \\
\hline & & $F$ & $P>F$ & $F$ & $P>F$ & $\boldsymbol{F}$ & $P>F$ & $\boldsymbol{F}$ & $P>F$ & $\boldsymbol{F}$ & $P>F$ & $\boldsymbol{F}$ & $P>F$ \\
\hline Cultivar (C) & 10 & 30.98 & $<0.0001$ & 23.05 & $<0.0001$ & 15.27 & $<0.0001$ & 46.95 & $<0.0001$ & 26.73 & $<0.0001$ & 30.70 & $<0.0001$ \\
\hline Isolates (I) & 13 & 65.27 & $<0.0001$ & 126.84 & $<0.0001$ & 35.67 & $<0.0001$ & 13.14 & $<0.0001$ & 9.72 & $<0.0001$ & 7.27 & 0.0001 \\
\hline$(\mathrm{C} \times \mathrm{I})$ & 130 & 1.32 & 0.0140 & 1.36 & 0.0083 & 1.21 & 0.0717 & 1.64 & $<0.0001$ & 1.14 & 0.1587 & 1.24 & 0.0455 \\
\hline
\end{tabular}

${ }^{a}$ DSI was arcsin transformed. Visual scales of severity, PL, RW, and RL were log transformed. Experiments consisted of three replications (towels) for each treatment combination and two experiments for the rolled-towel assay. Petri-dish assay experiments consisted of three Petri dishes per treatment combination in an incomplete block design, and using soybean cultivars Ripley and Jack as a control for each block. Data were from 11 soybean cultivars and $14 F$. oxysporum isolates.
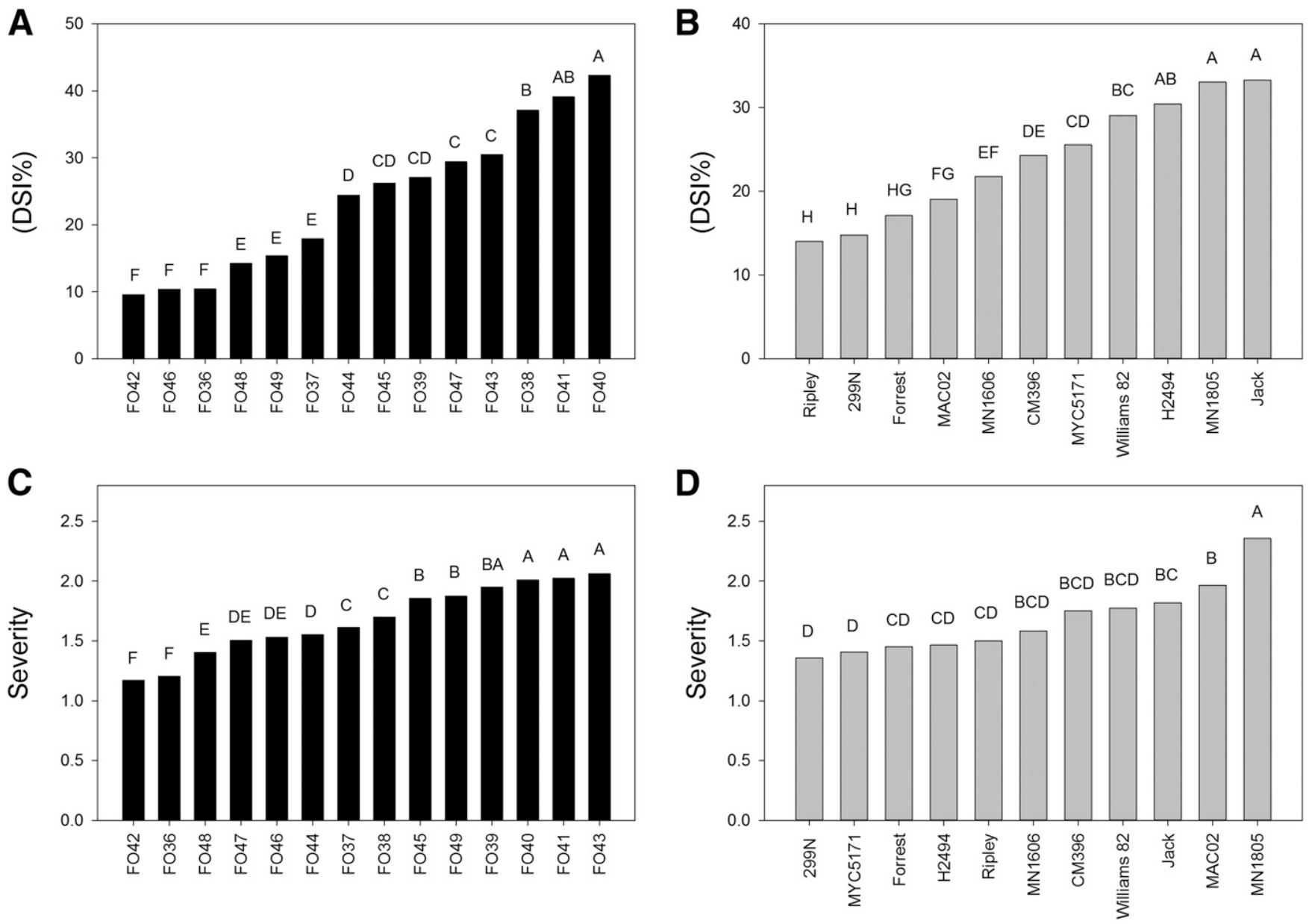

\section{F. oxysporum isolates}

\section{Soybean cultivars}

Fig. 3. A and B, Mean disease severity index (DSI\%) (rolled-towel assay) and C and D, visual severity rating (Petri-dish assay) for the main effects of isolate and soybean cultivar for Fusarium oxysporum isolates from lowa. Means with the same letter are not significantly different. Fisher's protected least significant difference $(P=0.05)$, arcsin transformed data for the rolled-towel assay. Data from the mock-inoculated seed were not included in the analysis. 
F. oxysporum conidia (macro- and microconidia) were collected from 7-day-old PDA pure cultures of each isolate by adding $10 \mathrm{ml}$ of SDW per plate and dislodging conidia from the surface with a sterile glass rod. Culture suspensions were passed through three layers of cheesecloth in order to avoid mycelial fragments, and conidia concentrations were adjusted to $2.0 \times 10^{5}$ conidia/ml using a hemacytometer. The adjusted conidia suspension $(100 \mu \mathrm{l})$ was added to a single Petri dish ( 60 by $15 \mathrm{~mm}$ ) containing PDA. Plates were incubated at $25^{\circ} \mathrm{C}$ under continuous light for $18 \mathrm{~h}$, then placed at $5^{\circ} \mathrm{C}$ and immediately scored for germination rate by direct observation under a light microscope at $\times 100$ magnification. One hundred arbitrarily selected conidia per plate were examined and considered germinated if the germ tube was twice the length of the conidium. The experimental design was completely randomized, with a factorial arrangement of fungicide, concentration, and isolate. There were three replicate Petri dishes per treatment combination.

Data analysis. For the rolled-towel assay, the percentage of DSI was arcsin transformed, and root length, plant length, and root weight were log transformed to meet the assumptions of the analysis of variance (ANOVA). Levene's test of homogeneity of variance was performed on the transformed data to compare the two experimental runs for each isolate separately using PROC GLM in SAS (version 9.3; SAS Institute Inc., Cary, NC). Because there were no significant differences between the two experimental runs, all data were combined and transformed, and ANOVA was performed using PROC GLIMMIX. In addition, the average of DSI and severity from each of the three replicate inoculated rolls per cultivar and $F$. oxysporum isolate were used to calculate linear correlation coefficients using the PROC CORR statement. For the Petri-dish assay, the nonparametric disease data from the response variable severity were analyzed using the PROC GLIMMIX statement in SAS. For the radial growth on PDA, Levene's tests of homogeneity and ANOVA were performed using PROC GLM. Data for the two experimental runs were combined because there were no significant differences between the variances. For all experiments, mean separation analyses were performed using a Fisher's protected least significant difference test at $P=0.05$.

The $50 \%$ effective concentration $\left(\mathrm{EC}_{50}\right)$ values for the growth inhibitors ipconazole and fludioxonil were calculated in a probit regression analysis. For each $F$. oxysporum isolate, the averaged percentage of growth inhibition on each dose was converted to a numerical equivalent of the probit function by using the normal inverse distribution function "NORMINV" in Excel (Microsoft). A linear equation was obtained from the regression between the logarithm of the doses and their respective probit values, and the $\mathrm{EC}_{50}$ was calculated to the corresponding dose value where probit was equal to

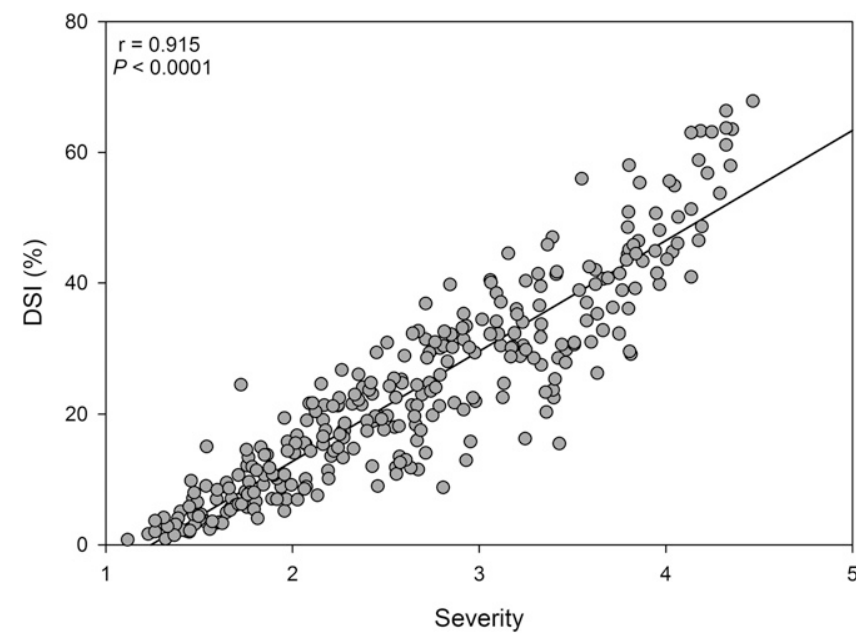

Fig. 4. Relationship between the visual scale for severity and disease severity index (DSI) for 11 soybean cultivars and 14 Fusarium oxysporum isolates for the rolled-towel assay. Each point represents an average of three towels containing 15 soybean seeds each for a particular isolate-cultivar combination.
0.5 . For the conidial germination inhibitors pyraclostrobin and trifloxystrobin, $\mathrm{EC}_{50}$ calculations were performed using the PROC PROBIT statement for each $F$. oxysporum isolate. Data for this analysis were based on the average of the percent inhibition as compared with the nonamended control.

\section{Results}

Rolled-towel pathogenicity assay. The ANOVA indicated a significant effect for the main factors soybean cultivar and $F$. oxysporum isolate, as well as a significant cultivar-isolate interaction for DSI $(P=0.0140)$ and the visual severity scale $(P=0.0083)$. These significant effects indicate that susceptibility varied among all cultivars and aggressiveness differed among the $F$. oxysporum isolates (Table 3).

Mean separation analysis for the main factors indicated a wide range of aggressiveness among isolates and susceptibility among cultivars. Not all isolates caused disease; in particular, FO36, FO42, and FO46 colonized the seed coat but no lesions or fungal colonization were observed in the radicle or hypocotyls. In contrast, isolates FO38, FO41, and FO40 predominantly produced seed rot symptoms (DSI $=100 \%$ ), causing poor germination (Fig. 3A).

Soybean cultivars used in this experiment differed in susceptibility when inoculated with $F$. oxysporum. Cultivars Ripley and $299 \mathrm{~N}$ had few symptoms of root rot regardless of isolate. Conversely, cultivars MN1805 and Jack displayed the greatest disease between isolates (Fig. 3B). The DSI ranged from $2.6 \%$ on Ripley soybean when inoculated with isolate FO46 and $60.8 \%$ on cultivar MN1805 when inoculated with isolate FO40 (data not shown).

The visual scale of severity presented results similar to those of the DSI. Visual severity ratings in the rolled-towel assay also indicated a significant interaction $(P=0.0455)$ between cultivars and isolates (Table 3). Furthermore, the two methods for root rot assessment (DSI and visual rating scale) were linearly correlated $(r=0.915$, $P<0.0001$ ) (Fig. 4). Pearson's correlation coefficients for the two disease evaluation methods were significant for all cultivars (Table 4).

Pathogenic isolates negatively affected plant development at different magnitudes. Plant length and root weight were significantly reduced for the plants inoculated with the highly aggressive isolates (FO38, FO41, and FO40) when compared with the noninoculated controls. Conversely, nonpathogenic isolates (FO42, FO46, FO36,

Table 4. Pearson correlation coefficients performed by soybean cultivar on disease severity index (DSI), plant length (PL), root length (RL), root weight (RW), and visual scale for severity

\begin{tabular}{ccccc}
\hline & \multicolumn{4}{c}{$\begin{array}{c}\text { Pearson correlations between DSI (\%) } \\
\text { and plant variables }\end{array}$} \\
\cline { 2 - 5 } Cultivar & PL & RL & RW & Severity \\
\hline Ripley & -0.71 & -0.44 & -0.49 & 0.88 \\
Prob $>|r|$ & $<0.0001$ & 0.0160 & 0.0070 & $<0.0001$ \\
$299 N$ & -0.61 & -0.39 & -0.25 & 0.86 \\
Prob $>|r|$ & 0.0005 & 0.0380 & 0.1890 & $<0.0001$ \\
Forrest & -0.72 & -0.42 & -0.32 & 0.87 \\
Prob $>|r|$ & $<0.0001$ & 0.0230 & 0.0920 & $<0.0001$ \\
MAC02 & -0.69 & -0.50 & -0.36 & 0.94 \\
Prob $>|r|$ & $<0.0001$ & 0.0060 & 0.0560 & $<0.0001$ \\
MN1606 & -0.72 & -0.63 & -0.08 & 0.95 \\
Prob $>|r|$ & $<0.0001$ & 0.0003 & 0.6540 & $<0.0001$ \\
CM396 & -0.73 & -0.31 & -0.21 & 0.94 \\
Prob $>|r|$ & $<0.0001$ & 0.0980 & 0.2720 & $<0.0001$ \\
MYC5171 & -0.41 & -0.22 & -0.13 & 0.93 \\
Prob $>|r|$ & 0.027 & 0.2580 & 0.4840 & $<0.0001$ \\
Williams82 & -0.68 & 0.02 & -0.08 & 0.97 \\
Prob $>|r|$ & $<0.0001$ & 0.8810 & 0.6590 & $<0.0001$ \\
H2494 & -0.79 & -0.59 & -0.64 & 0.97 \\
Prob $>|r|$ & $<0.0001$ & 0.0008 & 0.0002 & $<0.0001$ \\
MN1805 & -0.56 & -0.48 & -0.24 & 0.87 \\
Prob $>|r|$ & 0.001 & 0.0080 & 0.2180 & $<0.0001$ \\
Jack & -0.59 & -0.26 & -0.08 & 0.93 \\
Prob $>|r|$ & 0.0008 & 0.1780 & 0.6690 & $<0.0001$ \\
\hline & & & &
\end{tabular}



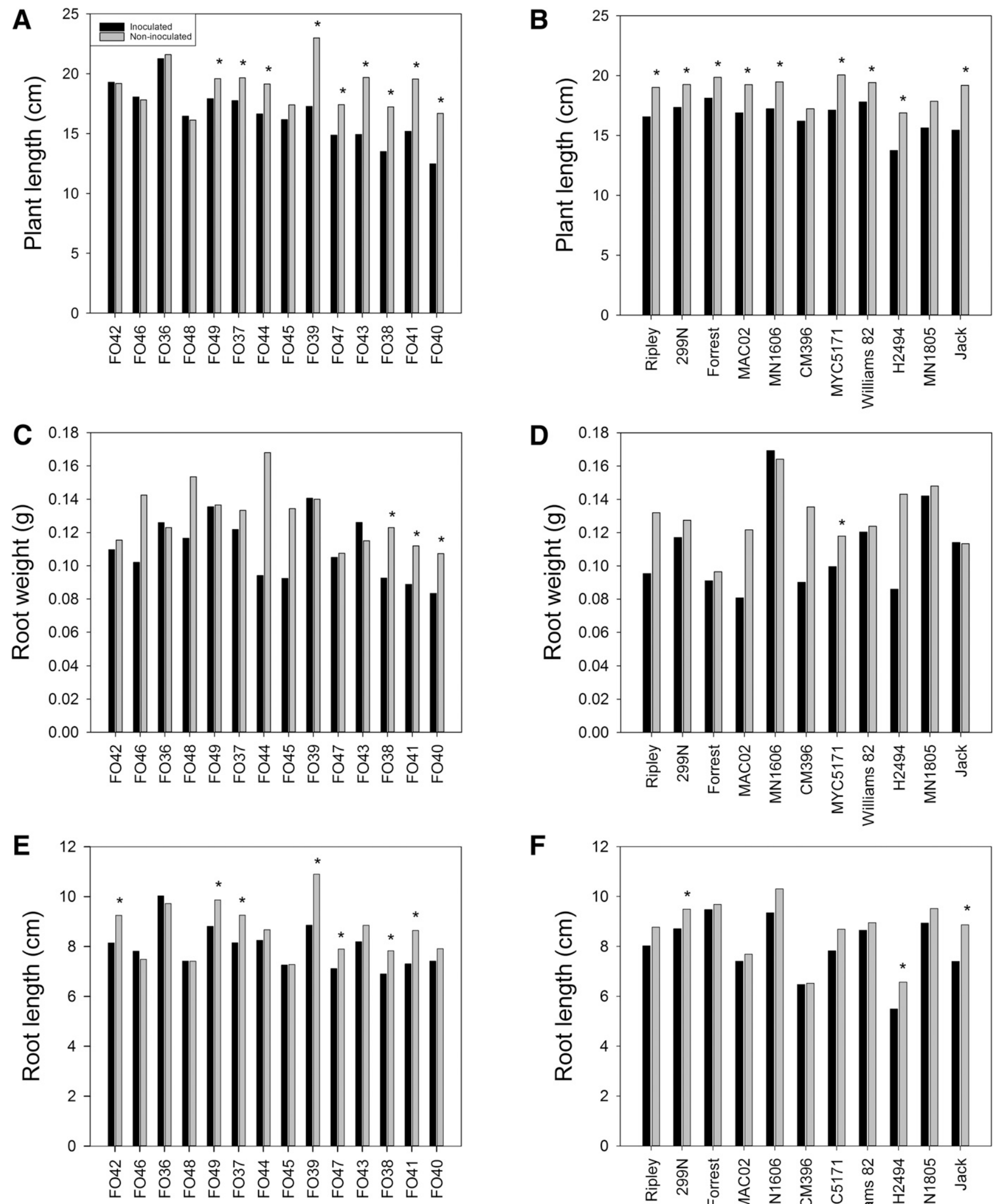

Fusarium oxysporum isolates

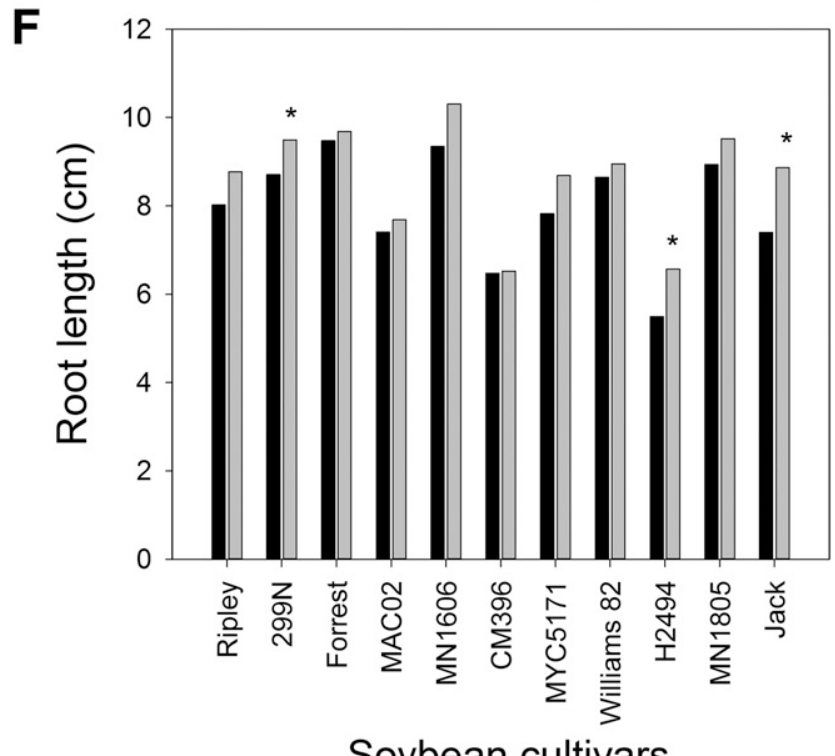

Soybean cultivars

Fig. 5. Differences in plant characteristics for the main effects of Fusarium oxysporum and soybean cultivar. $\mathbf{A}$ and $\mathbf{B}$, Plant length ( $\mathrm{cm}$ ); $\mathbf{C}$ and $\mathbf{D}$, root weight $(\mathrm{g})$; and $\mathbf{E}$ and $\mathbf{F}$, root length $(\mathrm{cm})$. An asterisk $\left(^{*}\right)$ indicates significant differences from the noninoculated control $(P=0.05)$ with a $t$ test for mean separation. Comparisons were made individually by isolate and soybean cultivar. 
and FO48), which showed the lowest levels of DSI, did not significantly affect the total plant length or root weight (Fig. 5A and C).

Cultivars CM396 and MN1805 did not display significant plant length reductions when inoculated with $F$. oxysporum (Fig. 5B). In addition, only 3 of the 11 cultivars showed reductions in root weight, and 2 displayed reductions in root length compared with noninoculated controls; only highly susceptible cultivars H2494 and Jack exhibited significant reductions in root length (Fig. 5D and F).

Pearson coefficients indicated a significant negative linear correlation between DSI and plant length $(r>0.05, P<0.0001)$. In contrast, plant variables such as root length and root weight were not strongly correlated with DSI for most of the cultivars (Table 4).

Petri-dish pathogenicity assay. Based on the visual severity scale for the Petri-dish assay (Fig. 2), cultivars varied in their susceptibility, and there was a significant interaction between the main factors cultivars and isolates $(P=0.0455)$ (Table 3$)$. Cultivars MN1805 and MAC02 were the most susceptible, showing poor germination and completely colonized seed. In contrast, cultivars $299 \mathrm{~N}$ and MYC5171 presented the lowest disease severity, with no symptoms or very small, dark-brown discoloration on seedling roots (Fig. 3D).

Aggressiveness and type of symptoms varied widely among isolates. Isolates such as FO36 and FO42 tended to be nearly

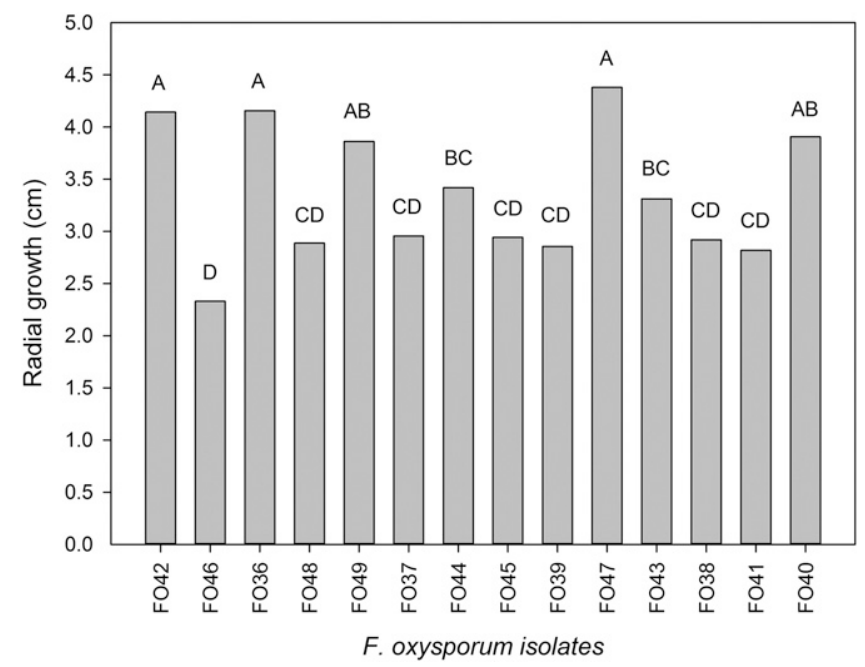

Fig. 6. Radial growth of 14 Fusarium oxysporum isolates on potato dextrose agar after 4 days at $24^{\circ} \mathrm{C}$ in the dark.

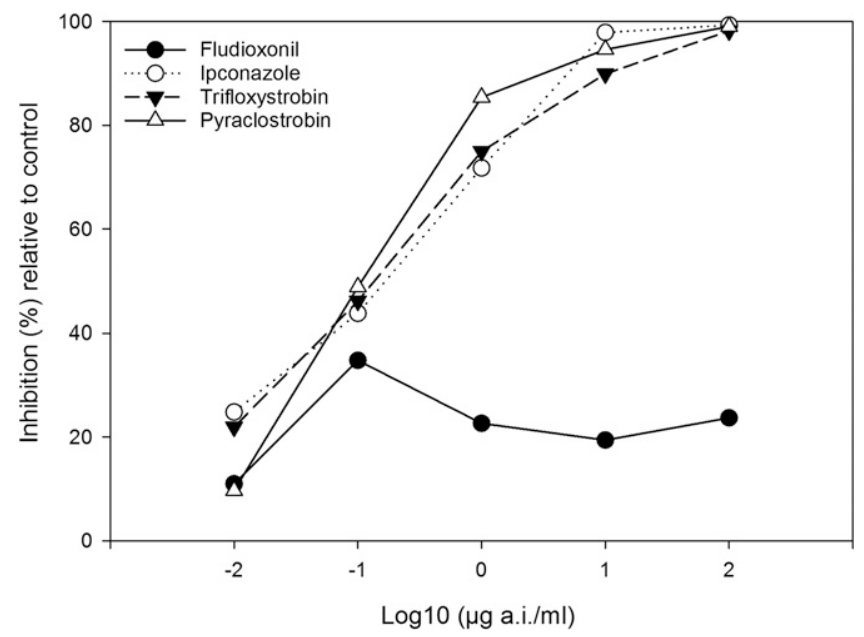

Fig. 7. Inhibitory effects of fungicides on radial growth (fludioxonil and ipconazole) and conidial germination (trifloxystrobin and pyraclostrobin) with respect to dose concentration on 14 Fusarium oxysporum isolates. nonpathogenic, producing small brown lesions on roots or no symptoms, such as in the cultivars MYC5171 and 299 N. In contrast, isolates FO40, FO41, and FO43 were highly aggressive, rapidly colonizing seed and causing preemergence damping-off. MN1805 was the most susceptible of the cultivars tested, with an average DSI of 2.8 and 2.7 when inoculated with FO40 and FO41, respectively. In addition, MN1805 was the most susceptible soybean cultivar when inoculated with 12 of the $14 F$. oxysporum isolates.

Radial growth on PDA. Radial growth at $25^{\circ} \mathrm{C}$ differed significantly $(P<0.001)$ among the $14 F$. oxysporum isolates. Radial growth after 4 days varied from $2.3 \mathrm{~cm}$ (FO46) to $4.3 \mathrm{~cm}$ (FO47). Isolates FO47, FO42, and FO36 had a significantly greater rate of growth than the rest of the isolates. Average growth of all isolates after 4 days was $3.34 \mathrm{~cm}$ (Fig. 6).

Fungicide sensitivity assays. Inhibition in radial growth of $F$. oxysporum isolates by fludioxonil was variable and did not appear to be affected by dose. As a result, an $\mathrm{EC}_{50}$ value for fludioxonil could not be calculated. Growth inhibition did not exceed $40 \%$ compared with the control (Fig. 7). In contrast, ipconazole effectively reduced the growth of all isolates; at the highest two concentrations (10 and $100 \mu \mathrm{g}$ a.i./ml), ipconazole inhibited growth by 97.3 and $99.3 \%$, respectively (Fig. 7). Ipconazole $\mathrm{EC}_{50}$ values varied among isolates; however, isolates FO38 and FO41 were least sensitive $\left(\mathrm{EC}_{50}\right.$ values of 0.747 and $1.667 \mu \mathrm{g}$ a.i./ml, respectively), while isolate FO40 was most sensitive to ipconazole $\left(\mathrm{EC}_{50}\right.$ value of $0.007 \mu \mathrm{g}$ a.i. $\left./ \mathrm{ml}\right)$ (Table 5).

QoI effectively inhibited conidial germination for all $F$. oxysporum isolates. At the highest concentrations (10 and $100 \mu \mathrm{g}$ a.i./ml), trifloxystrobin inhibited germination by 90 and $99 \%$, respectively. Pyraclostrobin performed better than trifloxystrobin for the $10 \mu \mathrm{g} / \mathrm{ml}$ concentration (94.6\% inhibition) (Fig. 7). Even though QoI displayed similar results, pyraclostrobin was more effective and had a mean $\mathrm{EC}_{50}$ value lower than that of trifloxystrobin (Table 5). Interestingly, pyraclostrobin $\mathrm{EC}_{50}$ values were high for individual isolates FO38 and FO41 (0.481, and $0.358 \mathrm{mg}$ a.i./liter, respectively), compared with the rest of the isolates. In addition, FO38 also showed a high $\mathrm{EC}_{50}$ for trifloxystrobin (1.479 $\mu \mathrm{g}$ a.i./ml) (Table 5).

\section{Discussion}

The current study provides information about the interaction of $F$. oxysporum with soybean cultivars and describes phenotypic diversity of $F$. oxysporum that may clarify its role in the Fusarium root rot complex. F. oxysporum isolates collected in Iowa displayed a high degree of variability in aggressiveness, ranging from almost nonpathogenic to highly aggressive. Similarly, soybean cultivars displayed a wide range of susceptibility, with some cultivars showing only small lesions on seedling tissues and a few other cultivars experiencing extensive colonization leading to low germination.

F. oxysporum is an important component of the Fusarium root rot complex in soybean, usually observed at a significantly greater frequency than other species of Fusarium in soybean roots (Díaz Arias et al. 2013b; Leslie et al. 1990; Nelson and Windels 1992). However, the role of $F$. oxysporum as a pathogen has been elusive due to the high degree of variability between isolates of the fungus. Although previous studies have reported significant differences in susceptibility among cultivars or aggressiveness among $F$. oxysporum isolates, each study has included only one isolate across several cultivars or vice versa. Therefore, conclusions regarding the previously published studies have proven to be contradictory, and suggest that $F$. oxysporum is either a primary pathogen or a secondary weak pathogen of soybean (Armstrong and Armstrong 1950, 1965; Ferrant and Carroll 1981; French and Kennedy 1963; Jester 1973; Killebrew et al. 1993; Zhang et al. 2010). The current study provides a more complete overview from the FOSC, including interactions among several isolates and soybean cultivars.

Using both rolled towel and Petri-dish assays, we were able to identify isolates that exhibited consistent levels of aggressiveness in causing both root rot and damping-off. Other isolates were aggressive at causing either damping-off or root rot but not both. This finding emphasizes the value of using assays that measure both root rot 
and damping-off to fully understand the impact of specific isolates on different soybean genotypes. The significant cultivar-isolate interactions suggests that the pattern of resistance for each soybean cultivar differs among isolates. Despite this interaction, we found that cultivars Ripley, Forrest, and $299 \mathrm{~N}$ were consistently among the most resistant to $F$. oxysporum in both assays. These cultivars may be useful sources of resistance for plant breeding.

A significant linear relationship $(P<0.001)$ between DSI and the visual severity scale in the rolled-towel assay suggests that these variables provide similar indications of susceptibility of soybean cultivars to infection by $F$. oxysporum. The visual severity scale is a more rapid technique to evaluate multiple cultivars compared with DSI. Although the visual scale is not as precise as the index based on lesion measurement, it was accurate enough to present similar ranking of the less susceptible cultivars and the most aggressive isolates to those obtained with DSI.

Assessments of plant growth characteristics were generally less useful in detecting the negative impact of $F$. oxysporum infection on seedling health. Significant reductions in plant length occurred due to $F$. oxysporum inoculation and plant length was negatively correlated with DSI. However, plant length was not a consistent indicator of susceptibility because some soybean cultivars that exhibited resistance based on DSI or visual severity still experienced a significant reduction in plant length. In addition, root weight and root length were highly variable within and among cultivars and were not correlated with DSI for most cultivars. These results are consistent with those of Zhang et al. (2010), who reported no significant correlations between plant growth variables and root rot severity caused by Fusarium spp. in soybean. Zhang et al. (2010) also reported that resistant soybean cultivars could display reductions in root dry weight and plant height as a result of inoculation with Fusarium spp. However, analysis of root weight reductions was more useful when it was performed by isolate, because it pinpointed the three most aggressive isolates (FO38, FO41, and FO40) compared with the noninoculated controls.

F. oxysporum isolates differed in colony morphology and radial growth when cultured on PDA media at $25^{\circ} \mathrm{C}$. This temperature has been widely reported as the optimum for growth of a majority of Fusarium spp. and, more specifically, for formae speciales of F. oxysporum from broad bean (Vicia faba L.), spinach, and banana (Groenewald et al. 2006; Ivanovic et al. 1987; Naiki and Morita 1983; Nelson et al. 1990). In the current study, differences is radial growth were not significantly correlated with isolate aggressiveness. For example, isolates FO41 and FO40 differed significantly in relative radial growth at $25^{\circ} \mathrm{C}$ but both isolates were judged to be aggressive; therefore, vegetative radial growth at $25^{\circ} \mathrm{C}$ was not an indicator of aggressiveness or clade placement within the FOSC.
It would be interesting to observe radial growth on these isolates at different temperatures and determine potential correlations to isolate pathogenicity.

Inhibition of spore germination by trifloxystrobin and pyraclostrobin indicated little variability in sensitivity to members of the QoI class of fungicides across $F$. oxysporum isolates with $\mathrm{EC}_{50}$ values ranging from 0.005 to $1.49 \mu \mathrm{g}$ a.i./ml. These findings contrast with previous research reporting that $F$. graminearum isolates collected from corn and soybean in Ohio exhibited reduced sensitivity to trifloxystrobin (Broders et al. 2007a). In that study, trifloxystrobin at the highest rate $(100 \mu \mathrm{g}$ a.i./ml) inhibited growth by less than $35 \%$ of the untreated control. Additionally, in the current study, ipconazole significantly reduced the growth of all $F$. oxysporum isolates. These findings agree with a previous report in which ipconazole significantly reduced Fusarium wilt caused by $F$. oxysporum f. sp. niveum in watermelon field trials (Everts et al. 2014). In addition, research suggests that ipconazole used in combination with QoI have positive effects on the emergence of chickpea infected with Aschochyta rabiei (Wise et al. 2009). Conversely, F. oxysporum isolates were observed to be insensitive to fludioxonil in the current study. These results indicate that fludioxonil activity may vary widely among species of Fusarium. For example, fludioxonil-resistant isolates in the genus Fusarium isolated from potato tubers have been reported in Canada and the United States (Gachango et al. 2012; Peters et al. 2008). Although the fludioxonil mode of action has not been elucidated, evidence suggests that the chemical targets the osmoticregulatory signal transduction pathway (Furukawa et al. 2012). However, resistance to fludioxonil may be conferred by multiple genetic and biochemical mechanisms (Kanetis et al. 2008; Ren et al. 2016). Conversely, fludioxonil has been reported to be effective against $F$. graminearum from soybean and maize when used as a seed treatment (Broders et al. 2007a; Ellis et al. 2011; Munkvold and O'Mara 2002). In other plant systems, fludioxonil has been reported to significantly reduce plant death in asparagus inoculated with $F$. oxysporum f. sp. asparagi and F. proliferatum (Reid et al. 2002), and improved stands of wheat under field conditions (Mueller et al. 1997).

Even though it would be difficult to determine whether the isolates used in the current research were exposed to the fungicides in the field prior to isolation, we believe this to be the case. The particular fungicides chosen are widely used active ingredients, and have been used for a considerable period of time as stand-alone seed treatment products, as well as in combination with additional active ingredients, for the control of seedling disease in soybean and maize (rotational hosts in the Iowa production system). Fludioxonil was introduced as a seed treatment for several crops, including soybean and maize, in 1994, and trifloxistrobin and pyraclostrobin were approved for the same use in 1999 and 2008, respectively (Munkvold

Table 5. Fungicide sensitivity analysis $\left(50 \%\right.$ effective concentration $\left.\left[\mathrm{EC}_{50}\right]\right)$ for 14 Fusarium oxysporum isolates recovered from soybean ${ }^{\mathrm{a}}$

\begin{tabular}{|c|c|c|c|c|c|c|}
\hline \multirow[b]{2}{*}{ Isolates } & \multicolumn{2}{|c|}{ Pyraclostrobin } & \multicolumn{2}{|c|}{ Trifloxystrobin } & \multicolumn{2}{|c|}{ Ipconazole } \\
\hline & $\mathrm{EC}_{50} \log _{10}(\mathrm{dose})$ & $E_{50}(\mu \mathrm{g}$ a.i. $/ \mathrm{ml})$ & $E_{50} \log _{10}($ dose $)$ & $\mathrm{EC}_{50}(\mu \mathrm{g}$ a.i. $/ \mathrm{ml})$ & $\mathrm{EC}_{50} \log _{10}($ dose $)$ & $\mathrm{EC}_{50}(\mu \mathrm{g}$ a.i. $/ \mathrm{ml})$ \\
\hline FO36 & -0.777 & 0.166 & -1.193 & 0.063 & -1.125 & 0.056 \\
\hline FO37 & -0.991 & 0.102 & -0.717 & 0.191 & -1.120 & 0.075 \\
\hline FO38 & -0.317 & 0.481 & 0.170 & 1.479 & -0.747 & 0.747 \\
\hline FO39 & -1.025 & 0.094 & -1.040 & 0.091 & -1.095 & 0.080 \\
\hline FO40 & -1.392 & 0.040 & -1.331 & 0.046 & -2.109 & 0.007 \\
\hline FO41 & -0.445 & 0.358 & -1.560 & 0.027 & 0.222 & 1.667 \\
\hline FO42 & -1.222 & 0.059 & -1.661 & 0.021 & -0.972 & 0.106 \\
\hline FO43 & -1.164 & 0.068 & -1.238 & 0.057 & -1.107 & 0.078 \\
\hline FO44 & -0.758 & 0.174 & -0.519 & 0.302 & -1.099 & 0.079 \\
\hline FO45 & -1.156 & 0.069 & -2.236 & 0.005 & -1.271 & 0.053 \\
\hline FO46 & -0.641 & 0.228 & -1.126 & 0.074 & -1.165 & 0.068 \\
\hline FO47 & -0.990 & 0.102 & -0.521 & 0.300 & -1.248 & 0.056 \\
\hline FO48 & -0.949 & 0.112 & -1.469 & 0.033 & -1.018 & 0.095 \\
\hline FO49 & -0.905 & 0.124 & -0.761 & 0.173 & -1.109 & 0.077 \\
\hline Average & -0.909 & 0.155 & -1.085 & 0.204 & -1.068 & 0.231 \\
\hline
\end{tabular}

\footnotetext{
${ }^{\mathrm{a}} \mathrm{EC}_{50}$ values for the active ingredient (a.i.) fludioxonil were not calculated because there was no apparent inhibition of mycelial radial growth with respect to the
} nonamended control 
2009). To the best of our knowledge, there are no previous reports of sensitivity profiles on $F$. oxysporum isolates associated with soybean roots, and there is a lack of true baseline sensitivity data. These results serve as a reference for future studies and emphasize the need to include $F$. oxysporum isolates from other locations and to test these active ingredients in in vivo trials.

FOSC is a genetically diverse group with polyphyletic origins (Ellis et al. 2014). Not surprisingly, a great deal of variability was observed regarding genotypic and phenotypic characteristics among the isolates used in the current study. For example, there were highly aggressive isolates representing three different clades (clades 3, 5, and 6 ), and one clade (clade 5) contained isolates representing both high and low aggressiveness according to the DSI. These findings suggest that there is no clear association between aggressiveness toward soybean and genotypic clade defined by multilocus sequence analysis. Our results contrast with those of Ellis et al. (2014), in which isolates from clade 5 were more aggressive than isolates from clades 2 and 3 . The discrepancies between the two studies may have resulted from a greater range of disease levels exhibited across the 11 soybean cultivars tested in the current study compared with the single susceptible cultivar used by Ellis et al. (2014), and a greater number of isolates $(n=170)$ used in the phylogenetic studies compared with the 14 isolates used in the current research.

The most effective strategies to manage Fusarium root rot are crop rotation, high-quality seed, delayed planting, and fungicide seed treatments (Nelson 1999). However, it is important to remember that soybean seedling diseases and soybean root rot appear as a disease complex and, as a consequence, the interactions of the FOSC with other pathogens that reside in the soil outside the Fusarium genus may influence the effectiveness of these management strategies. In the future, generating information to address this particular topic may aid in the management of complex soil pathosystems, especially when choosing a seed treatment for a particular crop based on field history. In addition, cultivar resistance and the differences in isolate pathogenicity are a key point to explore possibilities in developing long-term plant breeding strategies (Zhang et al. 2013). For example, host transcriptome profiles have been developed for soybean plants inoculated with $F$. oxysporum isolates FO40 and FO36, identified to be pathogenic and nonpathogenic, respectively (Lanubile et al. 2015). Substantial differences were observed in the gene expression profiles in which FO40 activated stronger expression of defenserelated genes compared with the nonpathogenic FO36 (Lanubile et al. 2015). Finally, pathogenicity information generated in this study could be used to select nonpathogenic isolates that may serve as biocontrol agents for $F$. oxysporum.

\section{Acknowledgments}

We thank S. Cianzio, C. Schmidt, and J. Orf for providing the soybean cultivars used in this study and A. Kriss for her assistance with the statistical analysis.

\section{Literature Cited}

Armstrong, G. M., and Armstrong, J. K. 1950. Biological races of the Fusarium causing wilt of cowpeas and soybeans. Phytopathology 40:181-193.

Armstrong, G. M., and Armstrong, J. K. 1965. A wilt of soybean caused by a new form of Fusarium oxysporum. Phytopathology 55:237-239.

Balasu, A. G., Cristea, S., Zala, C. R., and Oprea, M. 2015. The biological growth parameters of the Fusarium oxysporum f. sp. glycines fungus. Rom. Biotechnol. Lett. 20:10921-10928.

Bernard, R. L., and Cremeens, C. R. 1988. Registration of 'Williams 82' soybean. Crop Sci. 28:1027-1028

Broders, K. D., Lipps, P. E., Paul, P. A., and Dorrance, A. E. 2007a. Evaluation of Fusarium graminearum associated with corn and soybean seed and seedling disease in Ohio. Plant Dis. 91:1155-1160.

Broders, K. D., Lipps, P. E., Paul, P. A., and Dorrance, A. E. 2007 b. Characterization of Pythium spp. associated with corn and soybean seed and seedling disease in Ohio. Plant Dis. 91:727-735.

Chapin, L. J. G., Wang, Y., Lutton, E., and Gardener, B. B. M. 2006. Distribution and fungicide sensitivity of fungal pathogens causing anthracnose-like lesions on tomatoes grown in Ohio. Plant Dis. 90:397-403.

Cianzio, S. R., Lundeen, P., Gebhart, G., Rivera-Velez, N., Bhattacharyya, M. K., and Swaminathan, S. 2016. Registration of AR11SDS soybean germplasm resistant to sudden death syndrome, soybean cyst nematode, and with moderate iron deficiency chlorosis scores. J. Plant Regist. 10:177-188.
Cooper, R. L., Martin, R. J., McBlain, B. A., Fioritto, R. J., St. Martin, S. K., CalipDuBois, A., and Schmitthenner, A. F. 1990. Registration of 'Ripley' soybean. Crop Sci. 30:963.

Díaz Arias, M. M., Leandro, L. F., and Munkvold, G. P. 2013a. Aggressiveness of Fusarium species and impact of root infection on growth and yield of soybeans. Phytopathology 103:822-832.

Díaz Arias, M. M., Munkvold, G. P., Ellis, M. L., and Leandro, L. F. S. 2013b Distribution and frequency of Fusarium species associated with soybean roots in Iowa. Plant Dis. 97:1557-1562.

Ellis, M. L., Arias, M. M. D., Jimenez, D. R. C., Munkvold, G. P., and Leandro, L. E 2013. First report of Fusarium commune causing damping-off, seed rot, and seedling root rot on soybean (Glycine max) in the United States. Plant Dis. 97:284-285.

Ellis, M. L., Broders, K. D., Paul, P. A., and Dorrance, A. E. 2011. Infection of soybean seed by Fusarium graminearum and effect of seed treatments on disease under controlled conditions. Plant Dis. 95:401-407

Ellis, M. L., Cruz, D. R., Leandro, L. F., and Munkvold, G. P. 2014. Genotypic and phenotypic characterization of fungi in the Fusarium oxysporum species complex from soybean roots. Phytopathology 104:1329-1339.

Everts, K. L., Egel, D. S., Langston, D., and Zhou, X. G. 2014. Chemical management of Fusarium wilt of watermelon. Crop Prot. 66:114-119.

Ferrant, N. P., and Carroll, R. B. 1981. Fusarium wilt of soybean in Delaware. Plant Dis. 65:596-599.

French, E. R., and Kennedy, B. W. 1963. The role of Fusarium in the root rot complex of soybean in Minnesota. Plant Dis. Rep. 47:672-676.

Furukawa, K., Randhawa, A., Kaur, H., Mondal, A. K., and Hohmann, S. 2012. Fungal fludioxonil sensitivity is diminished by a constitutively active form of the group III histidine kinase. FEBS Lett. 586:2417-2422.

Gachango, E., Hanson, L. E., Rojas, A., Hao, J. J., and Kirk, W. W. 2012 Fusarium spp. causing dry rot of seed potato tubers in Michigan and their sensitivity to fungicides. Plant Dis. 96:1767-1774.

Groenewald, S., van den Berg, N., Marasas, W. F. O., and Viljoen, A. 2006. Biological, physiological and pathogenic variation in a genetically homogenous population of Fusarium oxysporum f. sp. cubense. Austral. Plant Pathol. 35:401-409.

Hartman, G. L., Sinclair, J. B., and Rupe, J. C., eds. 1999. Compendium of Soybean Diseases. American Phytopathological Society, St. Paul, MN.

Hartwig, E. E., and Epps, J. M. 1973. Registration of 'Forrest' soybeans. Crop Sci. 13:287

Ivanovic, M., Dragicevic, O., and Ivanovich, D. 1987. Fusarium oxysporum f. sp. fabae as cause of rot root on broad bean in Yugoslavia. Zast. Bilja 38:373-380.

Jester, W. R. 1973. Soybean root rot and root morphology as affected by till and no-till after barley. Master's thesis, University of Delaware, Newark.

Kanetis, L., Forster, H., Jones, C. A., Borkovich, K. A., and Adaskaveg, J. E. 2008. Characterization of genetic and biochemical mechanisms of fludioxonil and pyrimethanil resistance in field isolates of Penicillium digitatum. Phytopathology 98:205-214

Killebrew, J. F., Roy, K. W., and Abney, T. S. 1993. Fusaria and other fungi on soybean seedlings and roots of older plants and interrelationships among fungi, symptoms, and soil characteristics. Can. J. Plant Pathol. 15:139-146.

Lanubile, A., Muppirala, U. K., Severin, A. J., Marocco, A., and Munkvold, G. P. 2015. Transcriptome profiling of soybean (Glycine max) roots challenged with pathogenic and non-pathogenic isolates of Fusarium oxysporum. BMC Genomics 16:1089-1102.

Laurence, M., Summerell, B., Burgess, L., and Liew, E. C. Y. 2014. Genealogical concordance phylogenetic species recognition in the Fusarium oxysporum species complex. Fungal Biol. 118:374-384.

Leath, S., and Carroll, R. B. 1982. Screening for resistance to Fusarium oxysporum in soybean. Plant Dis. 66:1140-1143.

Leslie, J. F., Pearson, C. A. S., Nelson, P. E., and Toussoun, T. A. 1990. Fusarium spp. from corn, sorghum, and soybean fields in the central and eastern United States. Phytopathology 80:343-350.

Luckew, A., Cianzio, S., and Leandro, L. 2012. Screening method for distinguishing soybean resistance to in resistant $\times$ resistant crosses. Crop Sci 52:2215-2223.

Marburger, D. A., Venkateshwaran, M., Conley, S. P., Esker, P. D., Lauer, J. G. and Ane, J. M. 2015. crop rotation and management effect on Fusarium spp. populations. Crop Sci. 55:365-376.

Michielse, C. B., and Rep, M. 2009. Pathogen profile update: Fusarium oxysporum. Mol. Plant Pathol. 10:311-324.

Mondal, S. N., Bhatia, A., Shilts, T., and Timmer, L. W. 2005. Baseline sensitivities of fungal pathogens of fruit and foliage of citrus to azoxystrobin, pyraclostrobin, and fenbuconazole. Plant Dis. 89:1186-1194.

Mueller, D., Wise, K., Dufault, N., Bradley, C., and Chilvers, M., eds. 2013 Fungicides for Field Crops. American Phytopathological Society, St. Paul, MN

Mueller, K., Fischer, W., Steinemann, A., and Leadbitter, N. 1997. Control of Fusarium spp. on wheat: Movement and efficacy of fludioxonil applied as a seed treatment. Cereal Res. Commun. 25:787-788.

Munkvold, G. P. 2009. Seed pathology progress in academia and industry. Annu. Rev. Phytopathol. 47:285-311.

Munkvold, G. P., and O'Mara, J. K. 2002. Laboratory and growth chamber evaluation of fungicidal seed treatments for maize seedling blight caused by Fusarium species. Plant Dis. 86:143-150. 
Munkvold, G. P., Watrin, C., Scheller, M., Zeun, R., and Olaya, G. 2014. Benefits of chemical seed treatments on crop yield and quality. Pages 89-103 in: Global Perspectives on the Health of Seeds and Plant Propagation Material, Plant Pathology in the 21st Century, Vol. 6. M. L. Gullino and G. Munkvold, eds. Springer Verlag, Heidelberg, Germany.

Muyolo, N. G., Lipps, P. E., and Schmitthenner, A. F. 1993. Anastomosis grouping and variation in virulence of Rhizoctonia solani associated with dry bean and soybean in Ohio and Zaire. Phytopathology 83:438-444.

Naiki, T., and Morita, Y. 1983. The population of spinach wilt fungus, Fusarium oxysporum f. sp. spinaciae, and the wilt incidence in soil. Ann. Phytopathol. Soc. Jpn. 49:539-544.

Nelson, B. D. 1999. Fusarium blight or wilt, root rot, and pod and collar rot. Pages 35-36 in: Compendium of Soybean Diseases. American Phytopathological Society, St. Paul, MN.

Nelson, B. D., and Windels, C. E. 1992. Pathogenicity of Fusarium spp. on soybean in the Red River Valley. (Abstr.) Phytopathology 82:994.

Nelson, P. E., Burgess, L. W., and Summerell, B. A. 1990. Some morphological and physiological characters of Fusarium species in sections Liseola and Elegans and similar species. Mycologia 82:99-106.

Nickell, C. D., Noel, G. R., Thomas, D. J., and Waller, R. 1990. Registration of 'Jack' soybean. Crop Sci. 30:1365.

Nyvall, R. F. 1976. Colonization of soybeans by species of Fusarium. Mycologia 68:1002-1010.

O’Donnell, K., Gueidan, C., Sink, S., Johnston, P. R., Crous, P. W., Glenn, A., Riley, R., Zitomer, N. C., Colyer, P., Waalwijk, C., van der Lee, T., Moretti, A., Kang, S., Kim, H. S., Geiser, D. M., Juba, J. H., Baayen, R. P., Cromey, M. G., Bithell, S., Sutton, D. A., Skovgaard, K., Ploetz, R., Kistler, H. C., Elliott, M., Davis, M., and Sarver, B. A. J. 2009. A two-locus DNA sequence database for typing plant and human pathogens within the Fusarium oxysporum species complex. Fungal Genet. Biol. 46:936-948.

Peters, R. D., Platt, H. W., Drake, K. A., Coffin, R. H., Moorehead, S., Clark, M. M., Al-Mughrabi, K. I., and Howard, R. J. 2008. First report of fludioxonilresistant isolates of Fusarium spp. causing potato seed-piece decay. Plant Dis. 92:172
Reid, T. C., Hausbeck, M. K., and Kizilkaya, K. 2002. Use of Fungicides and biological controls in the suppression of fusarium crown and root rot of asparagus under greenhouse and growth chamber conditions. Plant Dis. 86:493-498.

Ren, W. C., Shao, W. Y., Han, X., Zhou, M. G., and Chen, C. J. 2016. Molecular and biochemical characterization of laboratory and field mutants of Botrytis cinerea resistant to fludioxonil. Plant Dis. 100:1414-1423.

Reuveni, M., and Sheglov, D. 2002. Effects of azoxystrobin, difenoconazole, polyoxin B (polar) and trifloxystrobin on germination and growth of Alternaria alternata and decay in red delicious apple fruit. Crop Prot. 21:951-955.

Schmidt, C., Lundeen, P., Shenaut, M., Bond, J., and Cianzio, S. 2014. 2014 Soybean sudden death syndrome commercial variety test results. Online publication. Southern Illinois University Extension. http://web.extension. illinois.edu/nwiardc/downloads/55828.pdf

Schmidt, C., Shenaut, M., and Bond, J. 2009. Soybean sudden death syndrome commercial variety test results. Southern Illinois University Extension. National Soybean Checkoff Research Database. https://www.soybeanresearchdata.com/ Project.aspx?id=5053

Skovgaard, K., Rosendahl, S., O’Donnell, K., and Nirenberg, H. I. 2003. Fusarium commune is a new species identified by morphological and molecular phylogenetic data. Mycologia 95:630-636.

Tatalović, N. 2014. Influence of Heterodera glycines infection, plant age and water availability on foliar symptoms of sudden death syndrome, root symptom severity and root morphology of soybean plants infected by Fusarium virguliforme. Ph.D. dissertation, Iowa State University, Ames.

Wise, K. A., Henson, R. A., and Bradley, C. A. 2009. Fungicide seed treatment effects on seed-borne Ascochyta rabiei in chickpea. HortTechnology 19:533-537.

Zhang, B. Q., and Yang, X. B. 2000. Pathogenicity of Pythium populations from corn-soybean rotation fields. Plant Dis. 84:94-99.

Zhang, J. X., Xue, A. G., Cober, E. R., Morrison, M. J., Zhang, H. J., Zhang, S. Z., and Gregorich, E. 2013. Prevalence, pathogenicity and cultivar resistance of Fusarium and Rhizoctonia species causing soybean root rot. Can. J. Plant Sci. 93:221-236.

Zhang, J. X., Xue, A. G., Zhang, H. J., Nagasawa, A. E., and Tambong, J. T. 2010 Response of soybean cultivars to root rot caused by Fusarium species. Can. J. Plant Sci. 90:767-776. 